Please ensure that your abstract fits into one column on one page and complies with the Instructions to Authors

available from the Abstract Submission web page.

\title{
A seasonally resolved coral nitrogen isotope record from the Florida Keys: Implications for the impact of anthropogenic nitrogen on the Gulf of Mexico
}

YUWEI WANG', XINGCHEN T. WANG', JENNIFER A. FLANNERY $^{2}$, LAUREN T. TOTH ${ }^{2}$, JULIE N. RICHEY ${ }^{2}$, YICHI CHEN ${ }^{3}$, ZIXUAN C. RAO ${ }^{4}$, HAOJIA A. REN ${ }^{3}$, DANIEL M. SIGMAN ${ }^{4}$

'Department of Earth and Environmental Sciences, Boston College, Chestnut Hill, MA 02467, USA (*presenting author,wangabj@bc.edu)

'United States Geological Survey, 600 4th St. South, St. Petersburg, FL 33701, USA

'Department of Geosciences, National Taiwan University, 106 Taipei, Taiwan

Department of Geosciences, Princeton University, Princeton, NJ 08544, USA

Human activities have altered the global nitrogen cycle through the use of fertilizer and fossil fuels which contribute to eutrophication on land as well as in coastal waters. The nearshore zones of the Gulf of Mexico are impacted by excess nutrient inputs from the continental US, leading to increased hypoxia and harmful algal blooms over the last few decades. However, it remains to be tested if these anthropogenic nitrogen inputs and their downstream flow path have affected the open waters in the Gulf of Mexico. In this study, we generated a seasonally-resolved nitrogen isotope record $\left(\delta^{\prime} \mathrm{N}\right)$ using skeletal material from the coral, Siderastrea siderea, obtained from the Dry Tortugas National Park, Florida, USA. From 2000 to 2012, there is no statistically significant trend observed in the skeletal $\delta{ }^{\circ} \mathrm{N}$ record, despite the increasing coastal hypoxia and harmful algae blooms and the warming trend observed in the $\mathrm{Sr} / \mathrm{Ca}$ record from the same coral core. We speculate that the anthropogenic nitrogen inputs to the Gulf of Mexico are largely removed in coastal zones by sedimentary denitrification and/or anammox, limiting the impact on open waters. The coral skeletal $\delta{ }^{\prime} \mathrm{N}$ exhibits intra-annual variation of $0.5-1 \%$ which appears to reflect seasonality, with higher $\delta{ }^{\circ} \mathrm{N}$ mostly observed in the wintertime. This is in contrast to a previously published coral skeletal $\delta^{i} \mathrm{~N}$ record from the South China Sea, in which lower $\delta{ }^{\prime} \mathrm{N}$ was observed in the wintertime and resulted from increased depositon of low- $\delta$ ' $N$ anthropogenic atmospheric nitrogen associated with the East Asian winter monsoon. 